\title{
Measurement of pancreatic stone protein in the identification and management of sepsis
}

\author{
Philippe Eggimann'1, Yok-Ai Que² \& Fabien Rebeaud*,3 \\ ${ }^{1}$ Département des Centres Interdisciplinaires et de Logistique Médicale, Centre Hospitalier Universitaire Vaudois (CHUV), Lausanne, \\ Switzerland \\ ${ }^{2}$ Department of Intensive Care Medicine, Inselspital, Bern University Hospital, Bern, Switzerland \\ ${ }^{3}$ Abionic SA, Route de la Corniche 5, 1066 Epalinges, Switzerland \\ *Author for correspondence: fabien.rebeaud@abionic.com
}

Sepsis is a life-threatening syndrome characterized by a dysregulated host response to an infection resulting in multiple organ dysfunctions. Early diagnosis and management of sepsis is key to improve patient outcome but remains challenging. Despite extensive research, only few biomarkers have so far proven to be helpful in the diagnosis of sepsis. A novel protein biomarker, the pancreatic stone protein (PSP), is showing great promises. Several lines of evidences suggest that PSP has a higher diagnostic performance for the identification of sepsis than procalcitonin and C-reactive protein, and a strong prognostic value to predict unfavorable outcome at admission to intensive care unit. This review summarizes the current knowledge on the molecular mechanisms of PSP function and the clinical evidences available to highlight the relevance of this protein in the diagnosis and prognosis of sepsis.

First draft submitted: 5 June 2018; Accepted for publication: 26 October 2018; Published online:

23 January 2019

Keywords: diagnosis $\bullet$ diagnostics $\bullet$ infection $\bullet$ prognosis $\bullet$ PSP • sepsis

\section{The burden of sepsis \& its challenges for its diagnosis \& management}

Sepsis is a recognized global health problem. It affects over 30 million people worldwide annually and is the largest killer of children $->5$ million each year [1]. Despite considerable progress in the management of organ failures, sepsis and septic shock, sepsis is still associated with reported mortality rates around $30 \%$, although mortality rates can be much higher depending on the geographical location and access to healthcare facilities [2]. With $>$ UD $\$ 24$ billion each year, sepsis represents the first cost of hospitalization in the USA [3]. Sepsis is the number one cause for readmissions to the hospital [4], and sepsis survivors experience functional deficits and diminished quality of life, with persistent higher risk for long-term mortality.

In 2016, a task force convened by national societies proposed a new clinical definition of sepsis ('Sepsis-3 criteria'), in which sepsis is defined as life-threatening organ dysfunctions caused by a dysregulated host response to infection [5]. This new definition helps in identifying a subset of infected patients at higher risk of death due to organ damage and integrates the current understanding of the pathophysiological mechanisms of sepsis. The pathophysiology of sepsis is complex and relies on a combination of factors related to both the microorganism and the immune response of the host. It most often follows a sequence of events, including a hyperinflammatory phase, a persistent inflammation phase and, later on, an immunosuppressive and a catabolic phase, both usually characterized by a multiple organ dysfunction, reactivation of latent viral infections, a higher susceptibility to nosocomial infections, as well as long-term functional and cognitive declines [6]. Death can occur at any time, either during the hyperinflammatory response, or as a result of the immunosuppressive condition, the recurrence of infections and/or multiple organ dysfunction.

The measurement of severity scores, either at admission (APACHE II [acute physiology and chronic health evaluation] and/or SAPS II [simplified acute physiology score]) or daily during the intensive care unit (ICU) stay (i.e., sequential [sepsis-related] organ failure assessment [SOFA]) may help assessing the severity of the infection as well as the extent of organ dysfunction [5]. Increased severity scores are associated with increased mortality [7]. As no specific treatment exists to treat the dysregulated host response to infection, management of sepsis thus relies 
on prompt control of the source of infection, early administration of an effective antibiotic therapy and intensive support of organ dysfunction.

Early recognition of sepsis is essential and a major determinant of the disease's outcome, repeatedly emphasized by the WHO and the Surviving Sepsis Campaign $[8,9]$. However, up to now, it has proven to be challenging, especially because signs and symptoms of sepsis are nonspecific and biomarkers with high sensitivity and specificity are still lacking despite extensive research.

A large number of biomarkers have been or are currently studied. They are used to detect sepsis, to assess its severity, to help triaging patients, to predict sepsis outcome or to monitor the response to treatment. It is important to stress that the evaluation of biomarker performance should not be restricted to the assessment of its sensitivity, specificity or accuracy, but should also take into account its cost-effectiveness, its usability, availability and the total turnaround time. In the context of sepsis, point-of-care testing (POCT) is appealing, as it might provide clinicians with a rapid and readily available diagnostic value. Of note, the information obtained from biomarkers must be adapted to the clinical situation and/or the setting of the patient (i.e., ICU, intermediate care, Emergency Department [ED]).

Today, only few biomarkers are routinely used at the bedside of patients with suspect of sepsis: C-reactive protein (CRP) and procalcitonin (PCT). CRP is an acute-phase protein mostly secreted by the liver and whose plasma concentration increases rapidly upon stimulation by proinflammatory cytokines, such as IL-6. Discovered back in the 1930s [10], CRP is a nonspecific marker of inflammation: its blood concentration rises whenever an inflammatory process is present, such as in the case of trauma, surgery, bacterial, viral and fungal infection [11,12]. Immunoassays measuring CRP concentration are available since decades, relaying on several techniques such as ELISA, immunoturbidimetry, nephelometry and rapid immunodiffusion. Nowadays, CRP is measured in clinical laboratory at low cost and, thanks to its high plasma concentration (in the hundreds of milligrams per liter in healthy adults), most assays provide results in a relatively short time. Although the low specificity of CRP for sepsis and the absence of bedside measurement are major drawbacks, CRP is still widely used for both the diagnosis of sepsis and to monitor critically ill patient's response to treatment (reviewed in [12]).

PCT is a peptide precursor of the hormone calcitonin and is physiologically secreted by the thyroid gland. PCT is not detectable in healthy individuals and its level rises within hours in response to proinflammatory stimuli especially when of bacterial origin (PCT production is attenuated by IFN- $\gamma$ primarily secreted in response to viral infection) [13,14]. Major surgery, severe trauma, severe burns, prolonged cardiogenic shock, fungal and malarial infections may rise PCT as well, and as with any other biomarkers, interpretation of PCT levels thus requires careful assessment of the patient's clinical condition [13]. The clinical utility of single or repeated PCT measurement has been extensively studied in various clinical setting such as primary cares, ED and ICU. Several clinical scenarios, from diagnosis of bacterial infection to assessment of disease severity, were evaluated. In most of the cases, PCT sensitivity and specificity were higher than that of CRP. PCT is also used as a prognostic marker of mortality in ICU [15] and to monitor response to treatment, and especially to guide de-escalation of antibiotic therapy. Indeed, the US FDA approved in 2017 the use of PCT for guiding antibiotic therapy in patients with acute respiratory infections [16]. Several reviews and meta-analyses summarizing the most recent findings are available elsewhere $[13,17]$. PCT is nowadays measured in clinical laboratories by immunoassay techniques; it is relatively costly, especially when compared with CRP. No technique is currently available for real-time bedside usage.

Other biomarkers, such as soluble CD25 and middle region of pro-adrenomedullin are currently evaluated in various clinical situations, including the diagnosis of sepsis, the monitoring of response to treatment, the diagnosis and prediction of organ dysfunction or the evaluation of sepsis and septic shock severity, and are reviewed elsewhere [18]. One emerging biomarker is attracting special attention: PSP, for pancreatic stone protein, shows promise as it is characterized by a higher accuracy in the diagnosis and prognosis of sepsis compared with CRP and PCT (Table 1).

\section{The pancreatic stone protein: structure, function \& its role in sepsis}

Originally, lithostathine and regenerating protein 1 (Reg I) have been discovered and described by different groups working on pancreatitis and diabetes. Later on, both proteins have been proven to be identical and were renamed PSP, for pancreatic stone protein [19,20]. PSP is encoded by a single transcript of the reg gene, resulting in a 144-amino acid length glycoprotein. This form is secreted into the duodenum along the same secretory pathway as the exocrine enzymes. Trypsin hydrolysis generates a polypeptide of 133 amino acids. Three disulfide bonds have been characterized and the protein is O-linked glycosylated on threonine in position 27. The functional 


\begin{tabular}{|c|c|c|c|c|c|c|c|c|c|}
\hline $\begin{array}{l}\text { Protein } \\
\text { biomarker }\end{array}$ & $\begin{array}{l}\text { Sensitivity to } \\
\text { detect } \\
\text { infection }\end{array}$ & $\begin{array}{l}\text { Specificity to } \\
\text { detect } \\
\text { infection }\end{array}$ & $\begin{array}{l}\text { Time window } \\
\text { of expression } \\
\text { upon infection }\end{array}$ & $\begin{array}{l}\text { Assessment of } \\
\text { the severity of } \\
\text { sepsis (organ } \\
\text { dysfunction) }\end{array}$ & $\begin{array}{l}\text { Prognostic } \\
\text { factor }\end{array}$ & $\begin{array}{l}\text { Used for } \\
\text { antibiotic } \\
\text { guidance }\end{array}$ & $\begin{array}{l}\text { Bedside } \\
\text { availability }\end{array}$ & $\begin{array}{l}\text { Time from } \\
\text { draw to } \\
\text { results } \\
\text { delivered to } \\
\text { clinicians }\end{array}$ & $\begin{array}{l}\text { Regulatory } \\
\text { status }\end{array}$ \\
\hline PSP & ++++ & ++++ & Days & ++++ & ++++ & N.D & Yes & $5 \mathrm{~min}$ & CE mark \\
\hline CRP & ++++ & + & Days & +++ & + & ++ & Yes & $>60 \mathrm{~min}$ & $\begin{array}{l}\text { CE mark, US FDA } \\
\text { cleared }\end{array}$ \\
\hline PCT & ++++ & +++ & Days & ++ & ++ & +++ & Yes & $>60 \mathrm{~min}$ & $\begin{array}{l}\text { CE mark, US FDA } \\
\text { cleared }\end{array}$ \\
\hline IL-6 & ++++ & ++ & Hours & ++++ & +++ & - & Yes & $>60 \mathrm{~min}$ & CE mark \\
\hline
\end{tabular}

roles of this protein have not been clearly elucidated, although structural homologies have been characterized to date: PSP is a globular polypeptide, which adopts the overall fold described for C-type lectins [21], which are calcium-dependent glycan-binding proteins known to have a diverse range of functions, including adhesion and signaling receptors in homeostasis and innate immunity, and are crucial in inflammatory responses and leukocyte and platelet trafficking [22].

The first function described for PSP was the inhibition of the growth and nucleation of calcium carbonate crystals in the pancreatic juice. Pancreatic juice is indeed characterized by high concentrations of calcium and carbonate ions, which can form pancreatic stones and calcium deposits in the pancreas, as in the case of chronic pancreatitis. As subsequent functional studies have brought conflicting results, it is nowadays a matter of debate whether PSP really plays a role in this function (discussed in [23]).

PSP has also been associated with pathological changes occurring in the pancreas during pancreatic inflammation [24] and, upon tryptic cleavage, with a calcium- and $\mathrm{pH}$-dependent bacterial binding to proteoglycan [25].

PSP levels were shown to be slightly higher in patients with Type-2 diabetes mellitus compared with healthy individuals [26. This level is even significantly higher in the subset of patients with diabetic kidney disease, a major complication of diabetes, and an important cause of end-stage renal disease [27].

A pivotal observation was made serendipitously in rat experiments by the group of Rolf Graf in which PSP was found to be an indicator of systemic stress [28]. This observation was then clinically confirmed in a cohort of trauma patients, in which serum PSP rises early after trauma for those patients that later develop infection and sepsis [29]. Reding et al. further showed that the pancreas senses remote organ damage and systemic stress and responds by secreting PSP, particularly when associated with septic complications [30].

Interestingly, incubation of whole blood from healthy volunteers in presence of recombinant PSP results in a dose-dependent increase of CD11b (a mediator of inflammation) and a decrease of CD62L (a transmembrane glycoprotein, which rapidly sheds from the cell surface upon activation) on polymorphonuclear neutrophil [29]. Yet it remains uncertain whether there is a direct interaction with a membrane-bound receptor as binding of PSP required a high concentration. This indicates that PSP might require a binding partner that subsequently induces activation of signaling pathways participating in the early events of the host response to pathogens.

Preclinical data showing that PSP might activate polymorphonuclear neutrophil, promote bacterial aggregation, being involved in the host response to pathogens via its C-type lectin domain, prompted its identification as potential biomarker for sepsis. Moreover, the observation that PSP level rose in response to septic insults in mice and rats encouraged its clinical evaluation as biomarker of sepsis in various settings and conditions.

\section{Diagnostic \& prognostic performance of PSP in sepsis}

PSP has been studied and compared with other biomarkers in various settings of infections and sepsis, both as a diagnostic marker of infection and/or sepsis, or a prognostic marker of disease outcome (Table 2). All studies available at the time of preparation of this review have been done using the former Sepsis- 2 criteria. It is likely (and desired) that ongoing and future studies will be done following the Sepsis-3 criteria.

In 12 out of 13 studies among various clinical settings (ED, ICU, surgical, nonsurgical adult and children), PSP proved to be more accurate, with a higher sensitivity, specificity, positive and negative predictive values than CRP, 
Table 2. Summary of clinical evidences pancreatic stone protein for diagnosis of infection and sepsis.

\begin{tabular}{|c|c|c|c|c|}
\hline Purpose of the study & Study population, characteristics & Results, main measurements & Conclusion & Ref. \\
\hline \multicolumn{5}{|l|}{ Physiological values } \\
\hline $\begin{array}{l}\text { PSP reference values in healthy } \\
\text { subjects }\end{array}$ & 397 healthy subjects & $\begin{array}{l}\text { PSP value (median [IQR]; ng/ml) } \\
<32 \text { wGA: } 2.6(2.0-4.3) \\
32 \text { wGA to } 36 \text { wGA: } 4.5(3.5-8.4) \\
37 \text { wGA to } 39 \text { wGA: } 6.3(4.0-10.2) \\
40 \text { wGA to }<1 \text { year: } 8.4(5.9-12.5) \\
61 \text { children (up to } 16 \text { year): } 16.1(12.0-20.1) \text {, } \\
61 \text { adults: } 10.8 \text { (7.6-12.5) }\end{array}$ & $\begin{array}{l}\text { PSP age-specific normal values, } \\
\text { which may be used to define cutoffs } \\
\text { for future trials. There is an } \\
\text { age-dependent increase of PSP from } \\
\text { birth to childhood }\end{array}$ & [31] \\
\hline \multicolumn{5}{|l|}{ PSP value in adults } \\
\hline $\begin{array}{l}\text { PSP level in post-traumatic } \\
\text { patients (serial measurement of } \\
\text { PSP) }\end{array}$ & $\begin{array}{l}83 \text { multiple trauma patients, } \\
18 \text { no infection, } \\
32 \text { local infections, } \\
33 \text { sepsis, } \\
38 \text { healthy control }\end{array}$ & $\begin{array}{l}\text { PSP (median }[\mathrm{IQR}] \text { in } \mathrm{ng} / \mathrm{ml}) \\
\text { Healthy volunteers: } 10.4(7.5-12.3) \mathrm{ng} / \mathrm{ml} \text {; } \\
\text { No infection: } \\
\text { Initial PSP: } 10.5(7.4-15.2), \\
\text { Maximal PSP: } 22.8 ; \\
\text { Local infection } \\
\text { Initial PSP: } 10.9(5.1-14.8) \text {, } \\
\text { Maximal: } 111.4 ; \\
\text { Sepsis: } \\
\text { Initial: } 10.6(6.9-16.3), \\
\text { Maximal: } 146.4\end{array}$ & $\begin{array}{l}\text { PSP is upregulated in blood after } \\
\text { trauma, and the PSP level is related } \\
\text { to the severity of inflammation. PSP } \\
\text { level mirrored the onset and peak of } \\
\text { sepsis }\end{array}$ & [29] \\
\hline $\begin{array}{l}\text { Diagnosis of sepsis in patients } \\
\text { admitted to ICU or high } \\
\text { dependency care units (PSP } \\
\text { measured within } 6 \text { h of } \\
\text { admission) }\end{array}$ & 219 unselected patients & $\begin{array}{l}\text { Accuracy (AUROCC) for sepsis versus no } \\
\text { sepsis with organ failures: } \\
\text { IL-6 }(>200 \mathrm{pg} / \mathrm{ml})=0.82(95 \% \mathrm{Cl} \text { : } \\
0.74-0.89), \\
\text { IL-8 }(>80 \mathrm{pg} / \mathrm{ml})=0.76(95 \% \mathrm{Cl}: 0.68-0.84) \text {, } \\
\text { IL-1b }(>1.0 \mathrm{pg} / \mathrm{ml})=0.77(95 \% \mathrm{Cl} \text { : } \\
0.69-0.85), \\
\text { HBP }(>50 \mathrm{ng} / \mathrm{ml})=0.58(95 \% \mathrm{Cl}: 0.48-0.68) \text {, } \\
\text { TNFa sCD } 25(>2.5 \mathrm{ng} / \mathrm{ml})=0.87(95 \% \mathrm{Cl} \text { : } \\
0.81-0.93), \\
\text { PCT }(>1.0 \mathrm{ng} / \mathrm{ml})=0.84(95 \% \mathrm{Cl}: 0.77-0.91) \\
\text { PSP }(>30 \mathrm{ng} / \mathrm{ml}) \text { : AUC } 0.91(95 \% \mathrm{Cl}: \\
0.86-0.96)\end{array}$ & $\begin{array}{l}\text { PSP outperforms other biomarkers, } \\
\text { including PCT, in patients with } \\
\text { suspected sepsis at the time of } \\
\text { admission to intensive or high } \\
\text { dependency care units }\end{array}$ & [32] \\
\hline $\begin{array}{l}\text { Prediction of outcome of } \\
\text { complication of postoperative } \\
\text { peritonitis patients }\end{array}$ & $\begin{array}{l}91 \text { postoperative peritonitis } \\
\text { patients admitted to the ICU. PSP } \\
\text { and PCT determined within } 3 \mathrm{~h} \\
\text { from admission to the ICU }\end{array}$ & $\begin{array}{l}\text { Accuracy (AUROCC) for: organ failure: } \\
\text { WCC }=0.38(95 \% \mathrm{Cl}: 0.27-0.50) \\
\text { CRP }=0.50(95 \% \mathrm{Cl}: 0.38-0.63) \\
\text { IL-6 }=0.61(95 \% \mathrm{Cl}: 0.48-0.74) \\
\text { PCT }=0.73(95 \% \mathrm{Cl}: 0.62-0.83) \\
\text { PSP }=0.81(95 \% \mathrm{Cl}: 0.71-0.90) \\
\text { Multiple organ failure: } \\
\text { WCC }=0.47(95 \% \mathrm{Cl}: 0.32-0.57) \\
\text { CRP }=0.53(95 \% \mathrm{Cl}: 0.40-0.65) \\
\text { IL-6 }=0.60(95 \% \mathrm{Cl}: 0-49-0.72) \\
\text { PCT }=0.71(0.60-0.82) \\
\text { PSP }=0.75(95 \% \mathrm{Cl}: 0.64-0.85) \\
\text { Death: } \\
\text { WCC }=0.49(95 \% \mathrm{Cl}: 0.34-0.64) \\
\text { CRP }=0.48(95 \% \mathrm{Cl}: 0.35-0.62) \\
\text { IL-6 }=0.64(95 \% \mathrm{Cl}: 0.51-0.76) \\
\text { PCT }=0.63(95 \% \mathrm{Cl}: 0.63-0.76) \\
\text { PSP }=0.77(95 \% \mathrm{Cl}: 0.67-0.88)\end{array}$ & $\begin{array}{l}\text { Among biomarkers, only serum PSP } \\
\text { measured at admission to the } \\
\text { surgical ICU is a reliable marker to } \\
\text { discriminate the severity of } \\
\text { peritonitis and the prediction of } \\
\text { death in the ICU, when compared } \\
\text { with CRP, WCC, IL- } 6 \text { and PCT }\end{array}$ & [33] \\
\hline $\begin{array}{l}\text { PSP value after cardiac surgery } \\
\text { and to identify infection and } \\
\text { sepsis (daily measurement of PSP) }\end{array}$ & $\begin{array}{l}120 \text { adult patients post -cardiac } \\
\text { surgery } \\
-18 \text { infections ( } 3 \text { sepsis) } \\
\text { - Pneumonia ( } 8 \text { ) } \\
\text { - UTI (3) } \\
\text {-Wound (4) } \\
\text { - Mediastinitis (1) }\end{array}$ & $\begin{array}{l}\text { Accuracy (AUROCC) for predication of } \\
\text { infection on day } 1 \text { post surgery: } \\
\text { CRP }=0.66 \text {, } \\
\text { WCC }=0.66 \text {, } \\
\text { PSP }=0.72 \text {; } \\
\text { Day } 2 \text { post surgery: } \\
\text { CRP }=0.53 \\
\text { WCC }=0.64 \\
\text { PSP }=0.76 \\
\text { Day } 3 \text { post surgery: } \\
\text { CRP }=0.58 \\
\text { WCC }=0.53 \\
\text { PSP } 0.74\end{array}$ & $\begin{array}{l}\text { PSP rises in all postcardiac surgery } \\
\text { patients. Levels of PSP at } \\
\text { postoperative days } 1-3 \text { has } \\
\text { discriminatory properties for } \\
\text { identifying infection early that is } \\
\text { superior to WCC and CRP }\end{array}$ & [34] \\
\hline \multicolumn{5}{|c|}{$\begin{array}{l}\text { This table summarized the key clinical findings of studies in which the PSP has been evaluated for different clinical situations on different patient populations. For most studies, PSP } \\
\text { has been compared with other standard or emerging biomarkers. } \\
\text { AUC: Area under the curve; AUROCC: Area under the receiving operator characteristic curve; CRP: C-reactive protein; ED: Emergency Department; HBP: Heparin binding protein; } \\
\text { hSCRP: High sensitivity C-reactive protein; ICU: Intensive care unit; IQR: Interquartile range; PCT: Procalcitonin; PSP: Pancreatic stone protein; SAPS: Simplified acute physiology } \\
\text { score; sCD25: Soluble CD25; SIRS: Systemic inflammatory response syndrome; UTI: Urinary tract infection; VAP: Ventilator-associated pneumonia; WCC: White cell count; WGA: } \\
\text { Weeks of gestational age. }\end{array}$} \\
\hline
\end{tabular}


Table 2. Summary of clinical evidences pancreatic stone protein for diagnosis of infection and sepsis (cont.).

\section{Purpose of the study}

PSP as a diagnostic marker for

infection and sepsis in ED
Study population, characteristics Results, main measurements

152 consecutive patients

admitted to ED (infection: 129 ,

including 47 with sepsis) Infection:
PSP as marker of organ failure in VAP and a prognostic marker for mortality
101 patients with clinically diagnosed VAP (sepsis, $n=25$ )
Accuracy (AUROCC) to predict:

SCD25 = 0.87 (95\% Cl: 0.80-0.94),

$\mathrm{PCT}=0.90$ (95\% Cl: 0.85-0.96),

$\mathrm{PSP}=0.84$ (95\% Cl: 0.77-0.90);

Sepsis:

sCD25 = 0.84 (95\% Cl: 0.76-0.91),

$\mathrm{PCT}=0.82$ (95\% Cl: 0.74-0.90),

$\mathrm{PSP}=0.87(95 \% \mathrm{Cl}: 0.81-0.94)$

Accuracy (AUROCC) of:

PSP at day 0 to predict survival (cutoff:

$24 \mathrm{ng} / \mathrm{ml})=0.69(95 \% \mathrm{Cl}: 0.57-0.8)$;

PSP at day 7 to predict death (cutoff: $177 \mathrm{ng} / \mathrm{ml})=0.76(95 \% \mathrm{Cl}: 0.62-0.91)$

PSP as an early biomarker
107 patients with severe sepsis or Accuracy (AUROCC) to: septic shock within $24 \mathrm{~h}$ of admission in a medico-surgical ICU

$\mathrm{CRP}=0.41$,

$\mathrm{PCT}=0.46$, predicting mortality in sepsis patients requiring ICU management

- predict death in sepsis patients

$\mathrm{PSP}=0.65$;

- predict death in septic shock patients CRP

$=0.44$,

PCT $=0.45$,

$\mathrm{PSP}=0.65$

PSP combined with severity scores to predict mortality in sepsis patients requiring ICU management

\section{9 patients with severe sepsis \\ Accuracy} $(n=93)$ or septic shock $(n=156)$

SAPS II $+\log (P S P)=0.66(95 \% \mathrm{Cl}$ :

0.56-0.76),

SAPS II + CRP + log(PSP $)=0.68(95 \% \mathrm{Cl}$

0.59-0.78),

SAPS II + CRP $+\log (P C T)+\log (P S P)=0.71$

(95\% Cl: 0.62-0.80)
Conclusion

PSP and soluble CD25 performed

well to detect infection and to

identify patients with sepsis in the

ED setting
PSP reflects organ

dysfunction/failure and outcome in VAP and allows stratifying patients with good and poor outcome

PSP measurement within $24 \mathrm{~h}$ of ICU admission predicts risk of in-hospital death more accurately than PCT and CRP

\section{PSP in infants and children}

PSP diagnostic values in early onset neonatal sepsis

52 uninfected neonates,

52 infected neonates
Accuracy (AUROCC) for infection

PSP (cutoff $13 \mathrm{ng} / \mathrm{ml}$ ) $=0.87$

CRP (cutoff $60 \mathrm{mg} / \mathrm{ml}$ ) $=0.81$
Initial PSP has a prognostic value in patients with severe sepsis and septic shock requiring ICU management. A model combining severity scores with PCT and PSP improves mortality prediction in these patients
PSP to predict neonatal sepsis

137 newborns, $<34$ wGA, 33 with Accuracy (AUROCC) to predict sepsis: infection, 104 without infection PCT (cutoff: $2 \mathrm{ng} / \mathrm{ml})=0.77(95 \% \mathrm{Cl}$ 0.66-0.87),

$\operatorname{PSP}(9 \mathrm{ng} / \mathrm{ml})=0.69(95 \% \mathrm{Cl}: 0.59-0.80)$, Combined $=0.83$ (95\% Cl: $0.74-0.93)$

PSP as diagnostic marker of sepsis-related organ failure in children
62 children admitted in ICU,

14 SIRS (no infection),

3 sepsis,

17 severe sepsis,

28 septic shock
Diagnostic characteristics to predict sepsis with organ failures:

Specificity $=0.92$, Sensitivity $=0.50$

Positive predictive value $=0.87$,

Negative predicative value $=0.65$, AUROCC $=0.70$

Accuracy (AUROCC) to predict death: $\mathrm{PSP}=0.83(95 \% \mathrm{Cl}: 0.77-0.88)$, $\mathrm{PCT}=0.76$ (95\% Cl: $0.70-0.82)$, hsCRP $=0.73$ (95\% Cl: 0.67-0.79), Combined $=0.92$ (95\% Cl: $0.87-0.95)$; $\mathrm{p}<0.001$
The high negative predictive value of PSP $(89.3 \%)$ indicates that the serum PSP level is a good marker for diagnosis of early onset neonatal sepsis

The diagnostic performance of PSP and PCT was superior to that of traditional markers and a combination of both improved the diagnosis of sepsis

PSP did not differ between patients with systemic inflammatory response syndrome and septic condition until organ dysfunction signs were present. Patients who died tended to have higher PSP levels

PCT, hsCRP and PSP levels predict outcome. Combination of all three biomarkers significantly improves the prediction.

PSP is a promising biomarker of risk and useful clinical tool for risk stratification of pediatric sepsis

$$
\begin{array}{ll}
\text { Accuracy (AUROCC) for diagnosis of acute } & \text { PSP and PCT are promising } \\
\text { osteomyelitis: } & \text { biomarker for early diagnosis of } \\
\text { PSP }=0.796(95 \% \mathrm{Cl}: 0.731-0.851) & \begin{array}{l}
\text { pediatric acute osteomyelitis. PSP } \\
\text { (cutoff }=26.5 \mathrm{ng} / \mathrm{ml}=
\end{array} \\
\mathrm{PCT}=0.767[95 \% \mathrm{Cl}: 0.700-0.826] \text { [cutoff] } & \begin{array}{l}
\text { AUROCC, while the combination of } \\
3.56 \mathrm{ng} / \mathrm{ml})
\end{array} \\
\text { PSP }+ \text { PCT }=0.903(95 \% \mathrm{Cl}: 0.851-0.941) & \text { high diagnostic performances }
\end{array}
$$

This table summarized the key clinical findings of studies in which the PSP has been evaluated for different clinical situations on different patient populations. For most studies, PSP has been compared with other standard or emerging biomarkers.

AUC: Area under the curve; AUROCC: Area under the receiving operator characteristic curve; CRP: C-reactive protein; ED: Emergency Department; HBP: Heparin binding protein; hSCRP: High sensitivity C-reactive protein; ICU: Intensive care unit; IQR: Interquartile range; PCT: Procalcitonin; PSP: Pancreatic stone protein; SAPS: Simplified acute physiology score; SCD25: Soluble CD25; SIRS: Systemic inflammatory response syndrome; UTI: Urinary tract infection; VAP: Ventilator-associated pneumonia; WCC: White cell count; WGA: Weeks of gestational age. 
PCT, IL-6 and other cytokines for the diagnosis of sepsis and prognosis of unfavorable outcome. In all these studies, PSP levels well correlated with disease severity, ranging from $<20 \mathrm{ng} / \mathrm{ml}$ in adult patients without infection to several hundred nanogram/milliliter in patients with severe sepsis and even several thousand nanograms/milliliters in the case of septic shock (Table 2).

A unique characteristic of PSP is that it may start to increase above the normal level range before the development of clinical signs and symptoms of sepsis. In a pivotal study, serial PSP measurements in multiple trauma patients were able to identify patients who were developing a sepsis before the rise of other biomarkers, and before the clinical diagnostic, in most cases [29]. The same has been reported in patients after cardiac surgery. In all 120 patients PSP levels raised after elective cardiac surgery, independently from the characteristics of surgery, but was significantly higher postoperatively, at 24, 48 and $72 \mathrm{~h}$ among the 18 patients (15\%) developing an infectious complication [34].

In a population of patients with sepsis-related complications, PSP levels have demonstrated a high diagnostic accuracy to discriminate the severity of peritonitis and to predict death in the ICU [33]. In another study, PSP levels reflected organ dysfunction and predicted death in ventilator-associated pneumonia (VAP), which allowed stratifying patients with good and poor outcome [36]. The value of PSP to predict in-hospital mortality in patients with severe sepsis and septic shock requiring ICU management has been further demonstrated by Que et al. [37], who also highlighted in another research that a model combining severity scores with PCT and PSP improves mortality prediction in these patients [38]. The clinical accuracy of PSP to identify sepsis and multiple organ dysfunction was also confirmed in a cohort of unselected, heterogeneous patients admitted to intensive or high-dependency care unit [32], as well as on a cohort of patients presenting to ED with suspicion of infection [35].

Data on the diagnostic performance of PSP for sepsis are also available for children and neonates. In children, the combination of PSP, PCT and CRP was superior to each of the individual markers for the risk stratification of pediatric sepsis [42], and the combination of PSP and PCT had significantly higher diagnostic accuracy for osteomyelitis than that of PSP or PCT alone [43]. In neonates, a population particularly at risk of sepsis and associated with high morbidity and mortality, a high negative predictive value of PSP, alone or in combination with PCT was found for early onset neonatal sepsis, which supports the concept of using PSP to rule out sepsis and thereby safely reduce antibiotic treatment in this specific population [39,40].

\section{Potential use of PSP in clinical diagnosis \& management of sepsis \& the need for short turnaround time}

The potential for the use of PSP alone or in combination with other sepsis biomarkers, especially CRP and PCT, is promising. The higher accuracy of PSP in the diagnosis of sepsis, its good correlation with the severity of organ failures and its unique prognostic value strongly argue for its use in the clinical setting (Table 2).

- PSP may be used to confirm the early suspicion of sepsis. PSP may thus allow reducing poorly justified 'emotional prescriptions' of antibiotic, a major goal of antibiotic stewardship programs;

- PSP may be used to stratify patients early according to disease severity, alone or in combination with routine severity scores such as APACHE II, SAPS II and SOFA;

- PSP may be used to stratify patients early according to prognosis and outcome, and thus allow correct triage and further management;

- PSP may ease screening and inclusion of septic patients in clinical trials.

Diagnosis of sepsis is especially challenging as the clinical signs and symptoms are not specific; most of the time a large overlap exists with noninfective causes of systemic inflammation. As early treatment of sepsis is associated with improved outcomes, rapid identification is key - every hour of delayed treatment represents increasing mortality [44].

High suspicion based on markers immediately available to the clinicians, such as body temperature, heart and respiratory rates, acute alteration of mental function and low blood pressures are neither sufficiently specific nor sensitive enough, even if used in combination as part of a clinical score [45]. Therefore, these scoring systems should be complemented with other parameters to improve their prognostic and/or diagnostic performances. In respect to that, blood host protein biomarkers represent certainly a promising approach, if (and only if) available within minutes to the clinicians.

Availability of PSP results within minutes from a drop of whole blood may bring a real breakthrough in the management of patients with sepsis or at risk of developing a sepsis. POCT has made tremendous progress in recent years and is today already commonly used for several applications in ED and ICU, such as for the bedside serial 


\begin{tabular}{|lll|}
\hline & Adhesion layer & Patient analyte (if present) \\
& Capture molecule & Fluorescently-labeled detecting antibody \\
& Non-fouling molecule & Other sample proteins \\
\hline
\end{tabular}

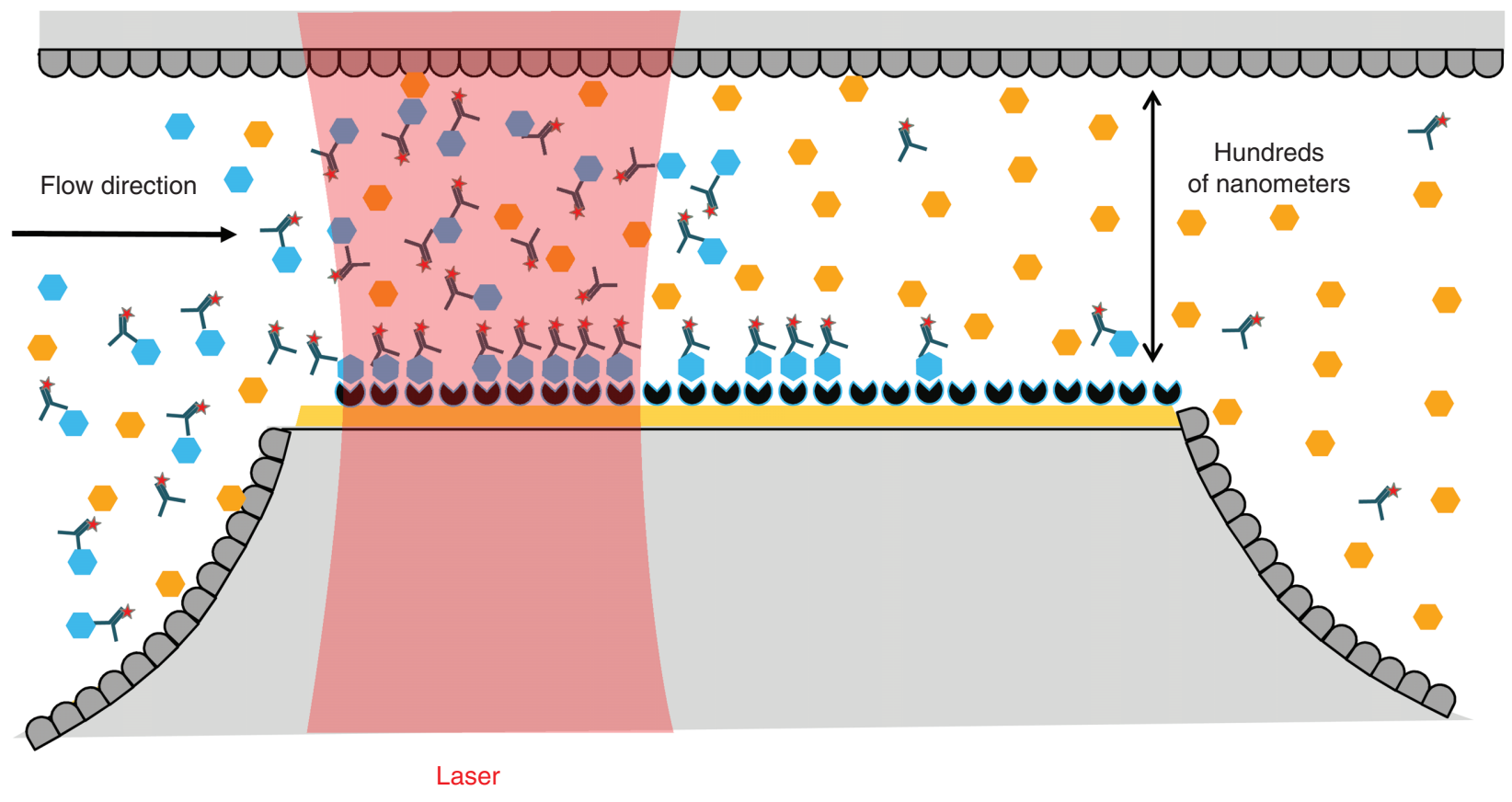

Figure 1. Lateral schematic view of a nanochannel; the high surface-to-volume ratio enhances capture of analyte to the solid phase. Sample is mixed with a detecting reagent and deposited at the entrance of a nanofluidic biosensors. The concentration of analyte is proportional to the fluorescence emitted by the detecting antibody label with a fluorophore. Reproduced with permission from [46] ๔ Springer Nature (2018).

measurement of blood gas, lactate, electrolytes or glucose. Implementing a novel POCT in these clinical settings is challenging (extensive training must be conducted to ensure good practices; quality controls are performed outside the clinical laboratory; test results must be incorporated to the hospital information system; POCT are more expensive than corresponding tests on large laboratory analyzers. ..). Therefore, advantages of using a POCT must counterbalance these limitations. This can be achieved through both proven clinical benefit of using a POCT and an economical benefit taking into consideration the entire patient stay. POCT has also an added advantage in settings where clinical laboratories cannot deliver results in the time consensually defined with clinicians, or when closed at night or weekends. New technologies are today requiring few or no preanalytical activities (to shorten hand-on time and mitigate risk of exposure of the operator to potentially biohazardous material), and have analytic performances meeting clinician's needs (in particular regarding accuracy, precision, analytical sensitivity and assay reportable range).

A recent technology based on nanofluidics (abioSCOPE, Abionic SA, Epalinges, Switzerland) allows quantifying proteins at the picomolar range from a drop of whole blood in a few minutes and without preanalytic work. Nanofluidic channels strongly influence the diffusional behavior of biomolecules and increase molecular interactions [43]. Due to the submicron structuration, the binding surface for the capture biomolecule is strongly increased, which enhances the sensitivity of the sensor and the biomolecular interaction leading to reduced assay times (Figure 1).

This technology has been used to develop a rapid PSP test, which is currently evaluated in ICU for the earlier detection of sepsis and represents an interesting solution as it combines two key requirements: short total turnaround 
time and a biomarker with high sensitivity and specificity to aid in identifying sepsis. As PSP is a biomarker giving information on urgent situations, future studies using PSP must be conducted at the bedside to clearly assess the benefit of obtaining PSP results within minutes for the management of sepsis patients and patients at risk of sepsis.

\section{Conclusion}

With an aging population worldwide, increasing prevalence of noncommunicable, chronic or serious illnesses associated with higher risk of sepsis (i.e., diabetes, obesity, malignancy...) and the threat of global antimicrobial resistances, sepsis incidences are unlikely to diminish in the near future. However, on the longer term, the combination of rapid diagnostic solutions, biomarker-guided therapies and an increased awareness of sepsis in both the community and among clinicians will contribute to reduce death and long-term complications of sepsis. The promising results obtained so far with the PSP in various clinical situations support that this biomarker has the potential to contribute to a better management of sepsis.

\section{Future perspective}

Despite an improved understanding of the pathophysiology of sepsis, a worldwide recognized need of earlier detection and the clinical evaluation of hundreds of proteins, metabolites, host and pathogen genetic markers, diagnosis and prognosis of sepsis remains a daily challenge for clinicians. Recent technological advancements and the discovery of novel promising markers open new avenues for the development of fast diagnostic solutions at the bedside, using measurements of biomarkers with high diagnostic accuracy for infection, sepsis and septic shock.

The agenda for further evaluation of the clinical utility of PSP should at least focus on:

- Demonstrating the impact of using PSP for: the early identification of sepsis in the ICU before the onset of typical signs and symptoms of sepsis; the prompt confirmation of sepsis in patients with clinical suspicion of infection (ICU, ED, out-patient clinic, nursing homes, ambulances...); and the risk stratification of septic patients and prognostication of their outcome to facilitate triage decision;

- Confirming the feasibility, clinical impact and economic benefit of serial real-time measurements of PSP in various settings, such as ICU and ED, using POCT technology (versus measurement in clinical laboratories);

- Bringing robust evidence, through large randomized trials, that bedside measurement of PSP in ED or in ICU is changing clinicians' behavior; thereby improving patient health outcome and potentially, adherence to antibiotic stewardship programs without jeopardizing patient safety;

- Finally, better understanding the molecular mechanisms of PSP function, in both healthy and septic patients, including a thorough understanding of the PSP kinetics (peak maximum level in presence of infection and/or sepsis and clearance upon resolution of the infection and/or organ dysfunction) and identification of medical conditions resulting in a rise of the PSP level independently of the presence of an infection or sepsis.

In addition, there are a couple of questions that need to be answered to clearly capture the potential of PSP compared with currently available biomarkers: how is PSP level evolving in patients with viral, fungal, parasitic, gram positive and negative bacteria? Is the PSP a reliable biomarker in neutropenic septic patients? What is the clinical utility of PSP for the identification of early onset neonatal sepsis, in particular in preterm babies? Are there any conditions leading to a rise of PSP levels that are not related to infection? As PSP is secreted mostly by the pancreas, could it be a marker of severity for pancreatitis? What is, if any, the clinical impact of combining PSP with other biomarkers? Would the combination of PSP with other established or new biomarkers and/or with scoring systems increase diagnostic accuracy of sepsis?

The first 5 years should allow finding answers to these specific open questions. Once the clinical utility of PSP has been confirmed within large studies, the five following years should push the PSP use outside the EDs and ICUs to more diverse patient populations and clinical situations. This is the only way to make PSP part of the standard of care.

In parallel, our better understanding of the pathophysiology of PSP in sepsis will probably allow better sorting septic patients, which may in turn improve management by selecting the intervention that suits most the patient condition.

Beside clinical research and clinical utility, the health economic benefit of measuring PSP at the point-of-care in different clinical scenario and patient populations must also be demonstrated to facilitate technology appraisal processes by national regulatory agencies. 


\section{Executive summary}

- Sepsis is a global health problem worldwide, and its diagnosis is today still challenging. Current blood biomarkers, used to help clinicians diagnosing sepsis, are neither enough sensitive nor specific.

- Pancreatic stone protein (PSP) is a protein secreted by the pancreas and its response to stress induced by systemic infection and sepsis.

- Several clinical studies performed in intensive care units and in Emergency Department have shown great potential of PSP measurement for early identification of sepsis and prediction of disease outcome. In those studies, PSP was systematically performing similarly or better than procalcitonin and C-reactive protein.

- More clinical data and a better understanding of the pathophysiological mechanisms of PSP function are needed to assess the potential of PSP as a disruptive biomarker for the early diagnosis of sepsis, in adults, children and neonates.

- As sepsis is a condition that demands an urgent intervention to increase chances of favorable outcome, rapid measurement at the bedside of PSP is an interesting approach to improve identification and management of septic patients.

\section{Authors' contributions}

P Eggimann and F Rebeaud participated in the drafting of the manuscript. P Eggimann, Y-A Que and F Rebeaud critically revised the manuscript. All authors have read and approved the final manuscript.

Financial \& competing interests disclosure

F Rebeaud is an employee of Abionic SA, a company developping a test to measure PSP, and owns options of Abionic SA. The authors have no other relevant affiliations or financial involvement with any organization or entity with a financial interest in or financial conflict with the subject matter or materials discussed in the manuscript apart from those disclosed.

No writing assistance was utilized in the production of this manuscript.

\section{Open access}

This work is licensed under the Attribution-NonCommercial-NoDerivatives 4.0 Unported License. To view a copy of this license, visit http://creativecommons.org/licenses/by-nc-nd/4.0/

\section{References}

1. Fleischmann C, Scherag A, Adhikari NKJ et al. Assessment of global incidence and mortality of hospital-treated sepsis. Current estimates and limitations. Am. J. Respir. Crit. Care Med. 193(3), 259-272 (2016).

2. Vincent JL, Marshall JC, Namendys-Silva SA et al. Assessment of the worldwide burden of critical illness: the Intensive Care Over Nations (ICON) audit. Lancet Resp. Med. 2(5), P380-P386 (2014).

3. Martin AB, Hartman M, Benson J, Catlin A; The National Health Expenditure Accounts Team. National health spending in 2014: faster growth driven by coverage expansion and prescription drug spending. Health Aff. (Millwood) 35(1), 150-160 (2016).

4. Mayr FB, Talisa VB, Balakumar V, Chang C-CH, Fine M, Yende S. Proportion and cost of unplanned 30-day readmissions after sepsis compared with other medical conditions. JAMA 317(5), 530 (2017).

5. Singer M, Deutschman CS, Seymour CW et al. The third international consensus definitions for sepsis and septic shock (Sepsis-3). JAMA 315(8), 801 (2016).

6. van der Poll T, Opal SM. Host-pathogen interactions in sepsis. Lancet Infect. Dis. 8(1), 32-43 (2008).

7. Seymour CW, Liu VX, Iwashyna TJ et al. Assessment of clinical criteria for sepsis: for the Third International Consensus Definitions for Sepsis and Septic Shock (Sepsis-3). JAMA 315(8), 762 (2016).

8. Reinhart K, Daniels Ron, N Kissoon. Recognizing sepsis as a global health priority - a WHO resolution. N. Engl. J. Med. 377(5), 414-417 (2017).

9. Rhodes A, Evans LE, Alhazzani W et al. Surviving sepsis campaign: international guidelines for management of sepsis and septic shock: 2016. Intensive Care Med. 43(3), 304-377 (2017).

10. Tillett WS, Francis T. Serological reactions in pneumonia with a non-protein somatic fraction of pneumococcus. J. Exp. Med. 52(4), 561-571 (1930).

11. Pepys MB, Hirschfield GM. C-reactive protein: a critical update. J. Clin. Invest. 111(12), 1805-1812 (2003).

12. Póvoa P. C-reactive protein: a valuable marker of sepsis. Intensive Care Med. 28(3), 235-243 (2002).

13. Samsudin I, Vasikaran SD. Clinical utility and measurement of procalcitonin. Clin. Biochem. Rev. 38(2), 59 (2017). 
14. Schuetz P, Bretscher C, Bernasconi L, Mueller B. Overview of procalcitonin assays and procalcitonin-guided protocols for the management of patients with infections and sepsis. Expert Rev. Mol. Diagn. 17(6), 593-601 (2017).

15. Schuetz P, Birkhahn R, Sherwin R et al. Serial procalcitonin predicts mortality in severe sepsis patients: results from the Multicenter Procalcitonin MOnitoring SEpsis (MOSES) study. Crit. Care Med. 45(5), 781-789 (2017).

16. Schuetz P, Wirz Y, Sager R, Christ-Crain M. Effect of procalcitonin-guided antibiotic treatment on mortality in acute respiratory infections: a patient level meta-analysis. Lancet Infect. Dis. 18(1), 95-107 (2018).

17. Schuetz P, Wirz Y, Sager R et al. Procalcitonin to initiate or discontinue antibiotics in acute respiratory tract infections. Cochrane Database Syst. Rev. 10, CD007498 (2017).

18. Rebeaud Fabien. Timely identification of sepsis: has the time (finally) come? Med. Lab. Obs. 49(8), 26-28 (2017).

19. De Caro Alain, Lohse Jürgen, Sarles Henri. Characterization of a protein isolated from pancreatic calculi of men suffering from chronic calcifying pancreatitis. Biochem. Biophys. Res. Commun. 87(4), 1176-1182 (1979).

20. Terazono K, Yamamoto H, Takasawa S et al. A novel gene activated in regenerating islets. J. Biochem. Chem. 263(5), 2111-2114 (1988).

21. Jin CX, Hayakawa T, Ko SB, Ishiguro H, Kitagawa M. Pancreatic stone protein/regenerating protein family in pancreatic and gastrointestinal diseases. Intern. Med. 50(15), 1507-1516 (2011).

22. Cummings RD, McEver RP. C-type lectins. In: Essentials of Glycobiology. Cold Spring Harbor Laboratory Press, NY, USA (2015). https://www.ncbi.nlm.nih.gov/books/NBK453028

23. Patard L, Lallemand J-Y, Stoven V. An insight into the role of human pancreatic lithostathine. JOP 4(2), 92-103 (2003).

24. Sarles H. Epidemiology and physiopathology of chronic pancreatitis and the role of the pancreatic stone protein. Clin. Gastroenterol. 13, 895-912 (1984).

25. Iovanna J, Frigerio J-M, Dusetti N, Ramare F, Raibaud P, Dagorn J-C. Lithostathine, an inhibitor of CaCO3, crystal growth in pancreatic juice, induces bacterial aggregation. Pancreas 8(5), 597-601 (1993).

26. Yang J, Li L, Raptis D et al. Pancreatic stone protein/regenerating protein (PSP/reg): a novel secreted protein up-regulated in Type 2 diabetes mellitus. Endocrine 48(3), 856-862 (2015).

27. Li L, Jia D, Graf R, Yang J. Elevated serum level of pancreatic stone protein/regenerating protein (PSP/reg) is observed in diabetic kidney disease. Oncotarget 8(24), 38145 (2017).

28. Graf R, Schiesser M, Lüssi A, Went P, Scheele GA, Bimmler D. Coordinate regulation of secretory stress proteins (PSP/reg, PAP I, PAP II, and PAP III) in the rat exocrine pancreas during experimental acute pancreatitis. J. Surg. Res. 105(2), 136-144 (2002).

29. Keel M, Härter L, Reding $T$ et al. Pancreatic stone protein is highly increased during posttraumatic sepsis and activates neutrophil granulocytes. Crit. Care Med. 37(5), 1642-1648 (2009).

30. Reding T, Palmiere C, Pazhepurackel C et al. The pancreas responds to remote damage and systemic stress by secretion of the pancreatic secretory proteins PSP/regI and PAP/regIII. Oncotarget 8(18), 30162 (2017).

31. Schlapbach LJ, Giannoni E, Wellmann S, Stocker M, Ammann RA, Graf R. Normal values for pancreatic stone protein in different age groups. BMC Anesthesiol. 15(168), doi:10.1186/s12871-015-0149-y (2015).

32. Llewelyn MJ, Berger M, Gregory M et al. Sepsis biomarkers in unselected patients on admission to intensive or high-dependency care. Crit. Care 17(2), R60 (2013).

33. Gukasjan R, Raptis DA, Schulz H-U, Halangk W, Graf R. Pancreatic stone protein predicts outcome in patients with peritonitis in the ICU. Crit. Care Med. 41(4), 1027-1036 (2013).

34. Klein HJ, Csordas A, Falk V et al. Pancreatic stone protein predicts postoperative infection in cardiac surgery patients irrespective of cardiopulmonary bypass or surgical technique. PLoS ONE 10(3), e0120276 (2015).

35. García de Guadiana-Romualdo L, Berger M, Jiménez-Santos E et al. Pancreatic stone protein and soluble CD25 for infection and sepsis in an Emergency Department. Eur. J. Clin. Invest. 47(4), 297-304 (2017).

36. Boeck L, Graf R, Eggimann P et al. Pancreatic stone protein: a marker of organ failure and outcome in ventilator-associated pneumonia. Chest 140(4), 925-932 (2011).

37. Que Y-A, Delodder F, Guessous I et al. Pancreatic stone protein as an early biomarker predicting mortality in a prospective cohort of patients with sepsis requiring ICU management. Crit. Care 16(4), R114 (2012).

38. Que Y-A, Guessous I, Dupuis-Lozeron E. Prognostication of mortality in critically ill patients with severe infections. Chest 148(3), 674-682 (2015).

39. Rass AA, Talat MA, Arafa MA et al. The role of pancreatic stone protein in diagnosis of early onset neonatal sepsis. BioMed. Res. Int. 2016, 1-8 (2016).

40. Schlapbach LJ, Graf R, Woerner A et al. Pancreatic stone protein as a novel marker for neonatal sepsis. Intensive Care Med. 39(4), 754-763 (2013).

41. Jiří Ž, Kýr M, Vavřina M, Fedora M. Pancreatic stone protein - a possible biomarker of multiorgan failure and mortality in children sepsis. Cytokine 66(2), 106-111 (2014). 
42. Wu Q, Nie J, Wu F, Zou X, Chen F. Prognostic value of high-sensitivity C-reactive protein, procalcitonin and pancreatic stone protein in pediatric sepsis. Med. Sci. Monit. 23, 1533-1539 (2017).

43. Cui C, Fu M, Gao B. Procalcitonin and pancreatic stone protein function as biomarkers in early diagnosis of pediatric acute osteomyelitis. Med. Sci. Monit. 23, 5211-5217 (2017).

44. Kumar A, Roberts D, Wood KE et al. Duration of hypotension before initiation of effective antimicrobial therapy is the critical determinant of survival in human septic shock. Crit. Care Med. 34(6), 1589-1596 (2006).

45. Vincent J-L, Moreno R. Clinical review: scoring systems in the critically ill. Crit. Care 14(2), 207 (2010).

46. Märk I, Rebeaud F. Nanotechnologies for in vitro IgE testing. Curr. Allergy Asthma Rep. 17(7), 50 (2017). 
